\title{
Pengelolaan Pemetikan Tanaman Teh (Camellia sinensis (L.) O Kuntze) di Unit Perkebunan Rumpun Sari Kemuning, Karanganyar, Jawa Tengah.
}

\section{Management of Tea Plucking (Camellia sinensis (L.) O Kuntze) at Unit Perkebunan Rumpun Sari Kemuning, Karanganyar, Central Java}

\author{
Anisa Windhita ${ }^{1}$, Supijatno ${ }^{1}$ \\ ${ }^{1}$ Departemen Agronomi dan Hortikultura, Fakultas Pertanian, Institut Pertanian Bogor \\ (Bogor Agricultural University), J1. Meranti, Kampus IPB Darmaga, Bogor 16680, Indonesia \\ Telp. \& Faks.62-251-8629353 e-mail agronipb@indo.net.id \\ *Penulis korespondensi: supijatno@yahoo.com
}

Disetujui 4 Mei 2016/ Published online 9 Mei 2016

\begin{abstract}
Internship activities was conducted in order to improve knowledge, field experience, and to study tea management aspect which is related to tea plucking. Internship activities was conducted at Perkebunan Rumpun Sari Kemuning, Karanganyar, Central Java from February until June 2013. Internship was conducted by direct and indirect methods. Direct method was conducted by doing and observing the field activity and interview actively. Indirect method was conducted by collecting management report, company archive and journal of tea research. Results showed that the height and diameter of pluck surface, maintenance foliage, the capacity of plucker, plucking round management and plucking area, and transportation were complied to PPTK Gambung standart. The increase in supervision of plucking analysis and shoots analysis were really important to get an optimal quality and quantity of tea shoots. Machine pruning more effective than manual pruning related to weights of pruning and time management. Production and HOK still need more employee to reach production target.
\end{abstract}

Keywords: plucking, Perkebunan Rumpun Sari Kemuning, tea, weights of pruning

\section{ABSTRAK}

Kegiatan penelitian dilaksanakan untuk memperluas pengetahuan, pengalaman teknis dan manajerial tanaman teh serta mempelajari aspek pemetikan. Kegiatan penelitian dilaksanakan di Perkebunan Rumpun Sari Kemuning, Karanganyar, Jawa Tengah pada bulan Februari sampai Juni 2014. Metode yang dilaksanakan selama kegiatan penelitian terbagi atas dua yaitu metode langsung dan tidak langsung. Metode langsung dilakukan secara aktif mengikuti dan mengamati kegiatan teknis di lapangan dan wawancara. Metode tidak langsung dilakukan dengan mengumpulkan laporan manajemen, arsip kebun dan jurnal penelitian teh. Hasil penelitian menunjukkan bahwa tinggi bidang petik, diameter bidang petik, tebal daun pemeliharaan, kapasitas pemetik, gilir dan hanca petik, dan sarana transportasi telah sesuai standar PPTK Gambung. Analisis petik dan analisis pucuk masih perlu peningkatan agar kuantitas dan kualitas pucuk yang optimal. Pemangkasan mesin lebih efektif daripada pemangkasan manual dinilai dari bobot brangkasan dan manajemen waktu. Produksi dan HOK masih memerlukan jumlah tenaga kerja dalam memenuhi target produksi.

Kata kunci: bobot brangkasan, pemetikan, Perkebunan Rumpun Sari Kemuning, teh 


\section{PENDAHULUAN}

Luas areal perkebunan teh Indonesia tahun 2005 adalah 139121 ha sedangkan pada tahun 2011 luas perkebunan teh Indonesia menurun menjadi 123938 ha. Pada data produksi pada tahun 2005 mencapai angka 166 091 ton daun kering sedangkan pada tahun 2011 produksi menurun sampai 150776 ton daun kering. Produktivitas teh pada tahun 2005 mencapai 1193 ton ha $^{-1}$ sedangkan pada tahun 2011 produktivitas 1216 ton $\mathrm{ha}^{-1}$. Penurunan luasan areal perkebunan teh akan menimbulkan penurunan produksi tanaman teh. Produksi teh dapat mempengaruhi volume ekspor teh. Pada data ekspor impor teh terdapat penurunan volume ekspor teh pada tahun 2005 dari 102389 ton menjadi 75450 ton pada tahun 2011. Data impor pada tahun 2005 memiliki volume impor 5 479 ton mengalami kenaikan pada tahun 2011 mencapai 19812 ton. Data tersebut menunjukkan bahwa produksi dan luas areal akan mempengaruhi volume kebutuhan ekspor dan impor Perkebunan Teh Indonesia (Ditjenbun, 2012). Kualitas pucuk teh yang memnuhi kriteria ekspor impor dapat ditentukan oleh budidaya tanaman teh yang baik dan aspek pemetikan pada setiap perkebunan.

Pemetikan merupakan suatu cara pengambilan daun yang dilakukan secara terus menerus berupa daun yang masih muda dan tunas yang sesuai dengan persyaratan dalam pengolahan teh. Kualitas pemetikan teh dipengaruhi oleh waktu pemetikan (Setyamidjaja, 2000). Waktu pemetikan dengan gilir dan hanca petik yang tepat akan menghasilkan produksi yang optimal. Ketinggian tempat akan mempengaruhi gilir petik dan waktu pemetikan tanaman teh. Mutu hasil teh bukan hanya ditentukan oleh ketinggian tempat tumbuh teh, melainkan dipengaruhi oleh sistem pemetikan (Johan dan Dalimoenthe, 2009).

Kegiatan Penelitian ini memiliki tujuan umum meningkatkan mengetahuan dan pengalaman aspek pemetikan daun teh serta menambah dan mengembangkan keterampilan yang diperoleh di lapangan dan membandingkannya dengan teori yang didapatkan di bangku kuliah. Selain itu kegiatan penelitian memiliki tujuan khusus yaitu mempelajari aspekaspek pemetikan dan faktor-faktor yang berpengaruh terhadap produksi tanaman teh.

\section{BAHAN METODE}

Kegiatan penelitian dilaksanakan di Unit Perkebunan Rumpun Sari Kemuning,
Karanganyar, Jawa Tengah selama 4 bulan dari 10 Februari sampai 10 Juni 2014. Metode pelaksanaan penelitian dilakukan dengan kegiatan teknis di lapangan dan aspek manajerial pada berbagai tingkatan status seperti karyawan harian lepas, pendamping mandor, pendamping asisten kebun, dan pendamping asisten afdeling yang masing-masing tingkatan dilaksanakan selama 4 minggu. Data primer diperoleh dengan bekerja secara aktif dan pengamatan di lapang. Data sekunder diperoleh dari laporan manajemen, arsip di kantor induk dan kantor pabrik, serta melalui studi pustaka. Data primer terdiri atas tinggi bidang petik, diameter bidang petik, tebal daun pemeliharaan, bobot brangkas daun pangkas, analisis petik, analisis pucuk, gilir petik dan hanca petik, tenaga petik serta kapasitas petik. Pengamatan tanaman dilakukan pada tanaman dengan umur pangkas I-IV tahun setelah pangkas. Pengamatan bobot brangkasan daun pangkas dilakukan sesuai dengan blok yang dipangkas pada saat penelitian dengan kriteria intensitas pangkas dan umur setelah pangkas. Data sekunder yang diamati antara lain sarana panen dan transportasi pucuk dan data produksi dan $\mathrm{HOK}$ berdasarkan umur pangkas.

Analisis data dan informasi dilakukan dengan menggunakan hasil rata-rata dari pengamatan yang telah dilakukan, hasil wawancara, dan studi pustaka. Data yang diperoleh dianalisis secara kuantitatif dan kualitatif nilai rata-rata dan diuraikan secara deskriptif dengan membandingkan standar perusahaan dengan studi pustaka dan melakukan analisis untuk mengetahui hubungan produksi dan faktor yang mempengaruhinya menggunakan uji t-student pada taraf 5\%. Nilai berbeda nyata apabila $\mathrm{t}$ hitung $>\mathrm{t}$ tabel dan tidak berbeda nyata apabila $\mathrm{t}$ hitung $<\mathrm{t}$ tabel, $\mathrm{t}$ tabel diperoleh dari nilai sebaran $\mathrm{t}$ pada taraf $5 \%$ dan $\mathrm{db}(\mathrm{n} 1+\mathrm{n} 2-2)$ (Walpole, 1992).

\section{KEADAAN UMUM}

Perkebunan Rumpun Sari Kemuning merupakan unit perkebunan teh yang terletak di Kelurahan Kemuning, Kabupaten Karanganyar, Jawa Tengah. Perkebunan teh ini terletak 11.1-11.25 ${ }^{\circ} \mathrm{BT}$ dan 7.4-7.6 ${ }^{\circ} \mathrm{LS}$ dengan ketinggian tanah 800-1540 m di atas permukaan laut (mdpl). Jenis tanah latosol dengan $\mathrm{pH}$ tanah 4.6-5.5 dengan topografi lahan yang landai bergelombang sampai berbukit dengan tingkat kemiringan wilayah $30-40^{\circ}$. Curah hujan di Unit Perkebunan Rumpun Sari Kemuning berdasarkan data curah hujan rata-rata selama 10 tahun terakhir (2003-2014) $3648.15 \mathrm{~mm}$ per tahun dan 
hari hujan rata-rata 152.72 hari hujan. Tipe iklim berdasarkancurah hujan menurut Schmidth Ferguson adalah tipe B. Suhu harian pada tahun 2013 di Perkebunan Rumpun Sari Kemuning berkisar antara $18.5-24{ }^{\circ} \mathrm{C}$ dengan kelembapan udara $(\mathrm{RH})$ berkisar antara $68-87 \%$ dan intensitas penyinaran antara $40-55 \%$ dengan suhu rata-rata $21.5^{\circ} \mathrm{C}$.

Berdasarkan sertifikat Hak Guna Usaha (HGU) memiliki luas areal 437.82 ha dengan area tanam 391.97 ha yang kemudian dibagi menjadi dua afdeling OA dan afdeling OB. Afdeling OA seluas 222.26 ha dengan area tertanam 214.26 ha terdiri dari 13 blok afdeling OA. Afdeling OB seluas 215.56 ha dengan area tertanam 177.71 ha terdiri dari 14 blok afdeling OB.

Varietas (klon) teh yang telah dibudidayakan antara lain: Klon TRI (Tea Research Institute of Ceylon, Srilangka) 2024, TRI 2025, Gambung (Puslitbun Gambung, Indonesia), dan CIN (Cinyiruan, Indonesia). Tanaman teh di Perkebunan Rumpun Sari Kemuning didominasi oleh klon TRI 2025. Jarak tanam yang digunakan adalah $120 \mathrm{~cm} \times 60 \mathrm{~cm}$ dengan populasi rata- rata 11430 pohon ha ${ }^{-1}$. Produksi pucuk teh 5 tahun terakhir (2009-2013) di Unit Perkebunan Rumpun Sari Kemuning memiliki rata-rata $3584190 \mathrm{~kg}$ tahun $^{-1}$ dengan produksi teh hijau kering sebesar $801981 \mathrm{~kg}$ tahun $^{-1}$. Rata-rata produktivitas teh basah 10 $403.78 \mathrm{~kg} \mathrm{ha}^{-1}$ tahun $^{-1}$ dengan produktivitas teh kering $2327.42 \mathrm{~kg} \mathrm{ha}^{-1}$ tahun $^{-1}$.

\section{HASIL DAN PEMBAHASAN}

\section{Tinggi Bidang Petik}

Tinggi rata-rata bidang petik pada umur pangkas I adalah $75.73 \mathrm{~cm}$; pada umur pangkas II dengan tinggi rata-rata $86.27 \mathrm{~cm}$; pada umur pangkas III dengan tinggi rata- rata $99.81 \mathrm{~cm}$; serta umur pangkas IV dengan tinggi rata-rata $106.06 \mathrm{~cm}$. Tinggi bidang petik ini sudah sesuai dengan ketentuan tinggi bidang petik tanaman teh yakni $>110 \mathrm{~cm}$. Tinggi bidang petik tersebut lebih ideal dibandingkan dengan pengamatan Martini (2011) yaitu tinggi bidang petik di Unit Perkebunan Rumpun Sari Kemuning dengan umur pangkas 4 tahun memiliki tinggi rata-rata 116.59 $\mathrm{cm}$. Menurut Johan dan Dalimoenthe (2009) tinggi bidang petik yang ideal untuk tanaman teh adalah 80-110 cm, sedangkan menurut Puslitbangbun (2010) ketinggian bidang petik tidak ergonomis bagi pemetik adalah $120-140 \mathrm{~cm}$. Tinggi bidang petik akan mempengaruhi kapasitas produksi basah pemetik dan hanca petik setiap harinya.

\section{Diameter Bidang Petik}

Pertumbuhan tanaman teh akan mempengaruhi pertambahan diameter bidang petik tanaman teh. Pertambahan diameter seiring dengan pertumbuhan umur pangkas teh. Pengamatan diameter bidang petik dapat dilihat di Tabel 1.

Tabel 1. Diameter bidang petik berdasarkan umur pangkas

\begin{tabular}{lcccc}
\hline \multirow{2}{*}{ Blok } & \multicolumn{4}{c}{ Diameter bidang petik pada tahun pangkas } \\
\cline { 2 - 5 } & I & II & III & IV \\
\hline OA 3 & 82.7 & $\ldots \ldots \ldots \ldots \ldots . .(\mathrm{cm}) \ldots \ldots \ldots \ldots \ldots .$. & \\
OA 5 & 85.6 & 97.8 & 100.8 & 125.2 \\
OA 14 & 87.5 & 98.6 & 102.1 & 138.1 \\
OB 7 & 83.4 & 97.3 & 102.7 & 122.3 \\
OB 11 & 82.8 & 96.6 & 109.1 & 124.7 \\
OB 15 & 83.1 & 98.2 & 208.3 & 138.4 \\
Rata-rata & $84.2 \mathrm{a}$ & $97.5 \mathrm{a}$ & $105.5 \mathrm{a}$ & 133.6 \\
\hline
\end{tabular}

Diameter bidang petik paling besar dimiliki oleh tanaman dengan umur pangkas IV. Rata-rata diameter bidang petik di Unit Perkebunan Rumpun Sari Kemuning berdasarkan umur pangkas I-IV adalah $84.2 \mathrm{~cm}$; $97.5 \mathrm{~cm}$; $105.5 \mathrm{~cm}$; dan $130.4 \mathrm{~cm}$. Diameter bidang petik rata-rata berdasarkan umur pangkas I-IV pada Unit Perkebunan Rumpun Sari Kemuning memiliki rata-rata diameter $104.4 \mathrm{~cm}$. Diameter bidang petik di Unit Perkebunan Rumpun Sari Kemuning lebih tinggi dibandingkan dengan diameter bidang petik dengan nilai rata-rata diameter berdasarkan umur pangkas I-IV adalah $94.42 \mathrm{~cm}$ (Fathan, 2013). Perbedaan besar lebar diameter disebabkan oleh tanaman yang diamati umumnya seedling karena dapat mempengaruhi lebar diameter bidang petik (Lelyana, 2011). Lebar diameter bidang petik tanaman dipengaruhi oleh umur pangkas, kesehatan tanaman, serta jenis klon. Tanaman yang sehat akan memiliki diameter bidang petik yang lebar. Tanaman perdu yang memiliki diameter yang lebar akan memiliki peluang besar dalam menghasilkan pucuk. Pada diameter yang terlalu lebar dapat mengganggu kegiatan pemetikan serta menutup jalan kontrol.

\section{Tebal Daun Pemeliharaan}

Tebal daun pemeliharaan akan menunjang dalam penyediaan hara untuk tanaman. Pemetikan mengakibatkan pembuatan zat pati berkurang untuk pertumbuhan tanaman. Pemetikan pucuk akan menghilangkan zat pati sekitar $7.5 \%$ (Puslitbangbun, 2010). Hasil pengamatan dapat dilihat pada Gambar 1. 
Unit Perkebunan Rumpun Sari Kemuning memiliki rata-rata tebal daun pemeliharaan 30.43 $\mathrm{cm}$. Tinggi tebal daun pemeliharaan berdasarkan umur pangkas antara lain umur pangkas I sebesar $28.7 \mathrm{~cm}$; umur pangkas II dengan tebal daun $30.10 \mathrm{~cm}$; umur pangkas III dengan tebal daun $30.62 \mathrm{~cm}$; serta umur pangkas IV dengan tebal paling besar yakni $32.3 \mathrm{~cm}$. Tebal daun pemeliharaan Perkebunan Rumpun Sari Kemuning sudah efektif. Menurut PPTK Gambung (2006), ketebalan lapisan daun pemeliharaan yang efektif untuk melakukan fotosintesis adalah setebal 4-5 lembar daun dan atau sekitar $15-20 \mathrm{~cm}$. Johan (2005) menyatakan bahwa daun pemeliharaan dengan tebal daun sekitar $20 \mathrm{~cm}$ cukup optimal untuk pertumbuhan pucuk teh. Seiring dengan bertambahnya umur pangkas akan bertambah juga tebal daun pemeliharaannya.

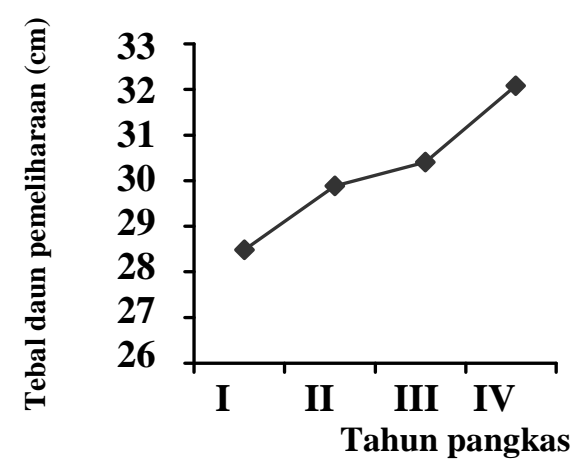

Gambar 1. Tebal daun pemeliharaan berdasarkan tahun pangkas tahun 2014

\section{Bobot Brangkasan Pangkas}

Kegiatan pemangkasan dilakukan dengan tujuan untuk mendapatkan ketinggian bidang petik yang optimal untuk pemetikan dan mendapatkan produktivitas tinggi. Pada Unit Perkebunan Rumpun Sari Kemuning melakukan perawatan pangkas disesuaikan dengan jumlah produksi yang dihasilkan pada blok yang akan dipangkas. Pengamatan bobot brangkasan dapat dilihat pada Tabel 2 .

Pemangkasan dilakukan dengan bantuan alat manual dan mesin. Pemangkasan manual menggunakan sabit dalam memangkas tanaman teh sedangkan pemangkasan dengan mesin menggunakan mesin pemotong rumput dengan modifikasi pisau berbentuk lingkaran. Metode pemangkasan dengan manual dan mesin berdampak pada bentuk pemangkasan tanaman teh dan bobot brangkasan pangkas teh. Pangkasan manual memiliki hasil pangkasan seperti mangkok dengan pada batang bagian tengah lebih pendek dan ujung batang runcing sehingga akan menghasilkan bidang petik yang datar pada saat pemetikan jendangan. Pangkasan menggunakan mesin menghasilkan ujung batang dan bidang permukaan lurus (tidak cekung di tengah).

Pangkasan manual dan pangkasan mesin pada intensitas dan umur pangkas yang sama terdapat perbedaan bobot brangkasan. Bobot brangkasan pangkas manual memiliki rata-rata $1.625 \pm 0.28 \quad \mathrm{~kg}$ sedangkan pada bobot brangkasan pangkas mesin memiliki rata-rata $1.279 \pm 0.15 \mathrm{~kg}$. Perbedaan rata-rata pangkas disebabkan karena pemangkasan mesin memotong brangkasan menjadi lebih pendek sehingga bobot brangkasan lebih kecil. Brangkasan ini selanjutnya digunakan untuk menutupi permukaan sampai layu dan digunakan sebagai tambahan bahan organik tanah. Hasil pengamatan ini memiliki nilai yang lebih kecil dibandingkan dengan pengamatan di Kebun Tambaksari PT Perkebunan Nusantara VIII dengan bobot brangkasan sebesar $5.9 \mathrm{~kg}$ pohon $^{-1}$ pada gilir pangkas 4 tahun dan tahun tanam sejak 1963 dengan pemangkasan manual (Asrimelwati, 2008). Hasil pengamatan yang berbeda diduga disebabkan oleh nutrisi hara tanaman, gilir pangkas dan tahun tanam yang berbeda pada Unit Perkebunan Tambaksari dan Unit Perkebunan Rumpun Sari Kemuning.

Tabel 2. Bobot brangkasan daun pangkas

\begin{tabular}{lrcc}
\hline \multirow{2}{*}{$\begin{array}{c}\text { Blok } \\
\text { pangkas }\end{array}$} & Pengamatan & \multicolumn{2}{c}{$\begin{array}{c}\text { Bobor brangkasan daun } \\
\text { pangkas }\end{array}$} \\
\cline { 3 - 4 } & & Pangkas manual & $\begin{array}{c}\text { Pangkas } \\
\text { mesin }\end{array}$ \\
\hline OA 4 & I & 1.85 & 1.35 \\
& II & 1.90 & 1.45 \\
OA 11 & III & 1.95 & 1.35 \\
& I & 1.55 & 1.25 \\
& II & 1.65 & 1.25 \\
OB 6 & III & 1.60 & 1.05 \\
& I & 1.75 & 1.35 \\
& II & 1.85 & 1.40 \\
OB 9 & III & 1.65 & 1.30 \\
& I & 1.35 & 1.10 \\
& II & 1.25 & 1.20 \\
\hline Rata-rata & III & 1.15 & 1.30 \\
\hline
\end{tabular}

\section{Analisis Petik}

Analisis petik adalah kegiatan memisahkan hasil petikan berdasarkan rumus petiknya. Analisis petik dilakukan dengan mengambil hasil petikan secara acak dari seluruh pemetik dan kemandoran. Tujuan dari analisis petik adalah menilai kesesuaian keterampilan pemetik dalam melakukan. 
Menurut Dalimoenthe (1999), analisis petik merupakan tahapan penilaian uji mutu. Analisis petik pada Unit Perkebunan Rumpun Sari Kemuning menunjukkan bahwa pemetik menghasilkan petikan medium dengan presentase $51.5 \%$. Petikan halus memiliki presentase $1.9 \%$; petikan kasar $31.43 \%$; dan petikan rusak $15.16 \%$. Presentase petikan halus dibawah 5\% dan petikan medium 50\% menunjukkan bahwa pemetikan dilakukan diatas bidang petik. Petikan medium masih kurang memenuhi ketentuan dikarenakan adanya pengaruh cara pemetikan, kondisi tanaman, dan gilir petik.

Tabel 3. Hasil analisis petik bulan April 2014

\begin{tabular}{lcccc}
\hline \multirow{2}{*}{ Mandor } & \multicolumn{4}{c}{ Komposisi pucuk (\%) } \\
\cline { 2 - 5 } & $\begin{array}{c}\text { Petikan } \\
\text { halus }\end{array}$ & $\begin{array}{c}\text { Petikan } \\
\text { medium }\end{array}$ & $\begin{array}{c}\text { Petikan } \\
\text { kasar }\end{array}$ & $\begin{array}{c}\text { Petikan } \\
\text { rusak }\end{array}$ \\
\hline MC & 1.65 & 50.50 & 29.85 & 18.00 \\
SP & 1.85 & 53.50 & 28.15 & 16.50 \\
SY & 1.45 & 52.50 & 32.55 & 13.50 \\
SG & 1.80 & 51.00 & 31.90 & 15.50 \\
TT & 2.15 & 51.50 & 30.35 & 16.00 \\
BB & 2.50 & 50.00 & 36.00 & 11.50 \\
\hline Rata-rata & $1.9 \pm 0.37$ & $51.5 \pm 1.30$ & $31.43 \pm 2.7$ & $15.16 \pm 2.3$ \\
\hline
\end{tabular}

\section{Analisis Pucuk}

Analisis pucuk adalah kegiatan pemisahan pucuk berdasarkan pada pucuk yang memenuhi syarat (MS) dan tidak memenuhi syarat (TMS) untuk diolah dan dinyatakan dalam persen. Analisis pucuk berguna untuk menilai kondisi pucuk yang akan diolah dan memperkirakan presentase mutu teh yang akan dihasilkan.

Analisis pucuk periode Januari sampai April memiliki rata-rata $31.3 \%$ memenuhi syarat (MS) dan $68.7 \%$ tidak memenuhi syarat (TMS). Presentase pucuk MS belum memenuhi standar yaitu minimal $40 \%$. Analisis pucuk ini merupakan dasar pemberian premi kepada mandor dan pemetik yang sesuai dengan ketentuan pabrik. Presentase pucuk MS yang kecil disebabkan masih tingginya persentase pucuk kasar dan pucuk rusak, serangan penyakit, dan pengangkutan pucuk dari kebun ke pabrik. Serangan penyakit menyebabkan pertumbuhan pucuk menjadi terhambat. Pengangkutan pucuk dari kebun ke pabrik yang melebihi kapasitas truk terkadang merusak kualitas pucuk.

Tabel 4 Hasil analisis pucuk di Unit Perkebunan Rumpun Sari Kemuning bulan Januari-April 2014

\begin{tabular}{lcccccccc}
\hline \multirow{2}{*}{ Mandor } & \multicolumn{2}{c}{ Januari } & \multicolumn{2}{c}{ Februari } & \multicolumn{2}{c}{ Maret } & \multicolumn{2}{c}{ April } \\
\cline { 2 - 10 } & MS & TMS & MS & TMS & MS & TMS & MS & TMS \\
\hline \multirow{2}{*}{ TT } & & & $\ldots \ldots \ldots \ldots \ldots \ldots \ldots \ldots \ldots \ldots \ldots \ldots \ldots(\%) \ldots \ldots \ldots \ldots \ldots \ldots \ldots \ldots \ldots \ldots \ldots \ldots \ldots$ & & \\
SN & 32.8 & 67.2 & 22.8 & 77.2 & 30.6 & 69.4 & 32.6 & 67.4 \\
GG & 33.2 & 67.2 & 30.8 & 69.2 & 34.3 & 65.7 & 34.5 & 65.5 \\
NY & 34.3 & 66.8 & 26.3 & 73.7 & 28.6 & 71.4 & 32.4 & 67.6 \\
BB & 28.6 & 71.4 & 26.8 & 73.2 & 39.4 & 60.6 & 33.2 & 66.8 \\
\hline Rata-rata & $32.3 \pm 2.17$ & $67.6 \pm 2.17$ & $27.5 \pm 3.83$ & 69.2 & 30.4 & 69.6 & 31.2 & 68.8 \\
\hline
\end{tabular}

\section{Gilir Petik}

Gilir petik adalah jangka waktu antara satu pemetikan dengan pemetikan berikutnya pada areal yang sama dan dinyatakan dalam satuan hari. Hasil pengamatan gilir petik dapat dilihat pada Tabel 5.Gilir petik yang tepat menghasilkan mutu pucuk yang memiliki mutu pucuk tinggi (Dalimoenthe, 1999). Panjang gilir petik bergantung pada kecepatan tumbuh pucuk yang dipengaruhi oleh iklim, umur pangkas, kesehatan tanaman dan ketinggian tempat. Ketinggian tempat dapat menentukan gilir petik tanaman teh. Pertumbuhan tanaman teh yang terletak di dataran tinggi memiliki kecepatan pertumbuhan pucuk yang lebih lambat karena tanaman teh mendapatkan intensitas cahaya dan suhu yang rendah serta kelembaban yang tinggi (PPTK Gambung, 2010).
Tabel 5. Gilir petik tahun 2014

\begin{tabular}{lrccc}
\hline Blok & $\begin{array}{c}\text { Ketinggian } \\
\text { Tempat } \\
\text { (m dpl) }\end{array}$ & $\begin{array}{c}\text { Luas } \\
\text { areal } \\
\text { (ha) }\end{array}$ & $\begin{array}{c}\text { Luas areal } \\
\text { petik/hari } \\
\text { (ha/hari) }\end{array}$ & $\begin{array}{c}\text { Gilir petik } \\
\text { (hari) }\end{array}$ \\
\hline OA 2 & 1080 & 20.76 & 1.5 & 14 \\
OA 3 & 1100 & 19.50 & 2.0 & 10 \\
OA 13 & 1060 & 14.83 & 2.5 & 6 \\
OB 4 & 880 & 14.15 & 2.0 & 7 \\
OB 8 & 1000 & 11.93 & 1.5 & 8 \\
OB 14 & 820 & 18.85 & 3.4 & 6 \\
\hline Rata-rata & & & $2.2 \pm 0.71$ & $8.5 \pm 3.08$ \\
\hline
\end{tabular}

Berdasarkan pengamatan dan data di kebun terlihat bahwa produksi pada blok yang terletak pada daratan tinggi diatas $1000 \mathrm{~m} \mathrm{dpl}$ memiliki gilir petik lebih lama antara 8-14 hari, sedangkan opada blok dengan ketinggian kurang dari $1000 \mathrm{~m}$ dpl memiliki gilir petik 6-7 hari. 
Selain itu juga dapat dipengaruhi oleh luas lahan blok yang dipetik.

Hanca Petik

Hanca petik adalah areal yang harus selesai dipetik oleh seorang pemetik dalam satu har. Hanca pemetik setiap blok berbeda karena dipengaruhi oleh kondisi pucuk, jumlah tenaga kerja dan topografi lahan.

Nilai hanca petik berbanding lurus dengan luas areal dan berbanding terbalik dengan gilir petik yang diterapkan. Semakin pendek gilir petik yang ditetapkan, maka hanca petik akan semakin besar dan begitupun sebaliknya (PPTK Gambung, 2006). Penetapan hanca petik setiap blok berbeda karena dipengaruhi oleh kondisi pucuk, tenaga petik dan topografi lahan. Semakin baik kondisi pucuk di lapang maka nilai hanca petik semakin besar, sedangkan jumlah tenaga petik berbanding terbalik dengan hanca petik (Fathan, 2013).

Tabel 6. Hanca petik bulan Januari-Mei 2014

\begin{tabular}{lccccc}
\hline \multicolumn{1}{c}{ Blok } & $\begin{array}{c}\text { Luas areal } \\
\text { (ha) }\end{array}$ & $\begin{array}{c}\text { Gilir petik } \\
\text { (hari) }\end{array}$ & $\begin{array}{c}\text { Pemetik } \\
\text { (orang) }\end{array}$ & $\begin{array}{c}\text { Hanca petik } \\
\text { (ha/hari/mandor) }\end{array}$ & $\begin{array}{c}\text { Hanca per pemetik } \\
\text { (ha/hari) }\end{array}$ \\
\hline OA 2 & 20.76 & 14 & 20 & 1.49 & 0.07 \\
OA 3 & 19.50 & 10 & 23 & 1.95 & 0.08 \\
OA 13 & 14.83 & 6 & 24 & 2.48 & 0.10 \\
OB 4 & 14.15 & 7 & 20 & 2.02 & 0.10 \\
OB 8 & 11.92 & 8 & 20 & 1.49 & 0.07 \\
OB 14 & 18.85 & 6 & 32 & 3.14 & 0.10 \\
Rata-rata & 16.67 & $8.5 \pm 3.08$ & $23.16 \pm 4.66$ & $2.09 \pm 0.63$ & $0.09 \pm 0.01$ \\
\hline
\end{tabular}

Penentuan hanca petik setiap blok ditentukan oleh masing-masing pembimbing petik. Nilai hanca petik pada Unit Perkebunan Rumpun Sari Kemuning sudah cukup baik bila dibandingkan dengan Unit Tambi PT Tambi Wonosobo yaitu sebesar 0.072 (Rahmadona, 2012) dan Unit Bedakah PT Tambi Wonosobo yaitu sebesar 0.030 (Fathan, 2013). Hal ini terjadi karena luas areal memiliki perbandingan yang berbeda dan jumlah tenaga kerja yang masih kurang untuk beberapa blok sehingga menurunkan hanca petik.

\section{Kapasitas Pemetik}

Kapasitas pemetik adalah banyaknya pucuk yang mampu dipetik oleh tenaga petik dalam satu hari kerja. Kegiatan pemetikan di Unit Perkebunan Rumpun Sari Kemuning menggunakan alat ani-ani atau salib, sabit, dan manual tangan dengan standar kapasitas pemetik (basic yield) sebesar $60 \mathrm{~kg} \mathrm{HK}^{-1}$. Kapasitas petik Unit Perkebunan Rumpun Sari Kemuning dapat dilihat pada Tabel 7 .

Tabel 7. Kapasitas pemetik bulan Januari-April 2014

\begin{tabular}{lccccc}
\hline \multirow{2}{*}{ Mandor } & Januari & Februari & Maret & April & \multirow{2}{*}{ Rata-rata } \\
\cline { 2 - 5 } SR & \multicolumn{5}{c}{ Kg/pemetik } \\
SN & 68.83 & 66.80 & 71.61 & 54.90 & 65.5 \\
TT & 51.95 & 58.81 & 65.39 & 61.12 & 64.3 \\
GG & 59.42 & 64.17 & 71.04 & 68.61 & 68.3 \\
SD & 63.89 & 67.96 & 73.51 & 70.42 & 68.9 \\
ST & 60.71 & 55.65 & 59.08 & 70.09 & 66.4 \\
\hline Rata-rata & 67.06 & 64.25 & 66.69 & 69.27 & 66.8 \\
\hline
\end{tabular}

Sumber : Laporan produksi Unit Perkebunan Rumpun Sari Kemuning 2014

Kapasitas pemetik di Unit Perkebunan Rumpun Sari Kemuning pada bulan JanuariApril 2014 yaitu $66.7 \mathrm{~kg}$ orang $^{-1}$. Nilai tersebut menunjukkan bahwa rata-rata kapasitas pemetik di Unit Perkebunan Rumpun Sari Kemuning sudah memenuhi standar yang telah ditetapkan. Produktivitas Unit Perkebunan Rumpun Sari Kemuning memiliki produktivitas tahun 2012 yaitu $2011.091 \mathrm{~kg} \mathrm{ha}^{-1}$ lebih tinggi dibandingkan dengan produktivitas nasional yaitu $1477 \mathrm{~kg} \mathrm{ha}^{-1}$
(Ditjenbun, 2012), sehingga Unit Perkebunan Rumpun Sari Kemuning memiliki standar peluang tinggi untuk mencapai target tahunan perkebunan teh nasional.

Hasil pengamatan menunjukkan bahwa kapasitas pemetik tidak dipengaruhi oleh umur (Tabel 8) dan lama pengalaman kerja (Tabel 9), pada hal ini kapasitas pemetik dipengaruhi oleh keadaan pucuk di lapang, keterampilan pemetik, jumlah pokok tanaman teh, umur tahun pangkas, 
cuaca dan topografi kebun. Kondisi kebun sangat mempengaruhi produksi tanaman teh yang akan dipetik.

Tabel 8. Kapasitas pemetik berdasarkan usia pemetik

\begin{tabular}{ccc}
\hline Usia (tahun) & Jumlah sampel & Rata-rata kapasitas \\
\hline $20-40$ & 10 & $68.2 \mathrm{a}$ \\
$41-55$ & 10 & $62.6 \mathrm{a}$ \\
\hline
\end{tabular}

Keterangan: Angka-angka yang diikuti huruf yang sama pada kolom yang sama menunjukkan nilai tidak berbeda nyata berdasarkan uji t-student dengan taraf $5 \%$.

Tabel 9. Kapasitas pemetik berdasarkan lama kerja pemetik

\begin{tabular}{ccc}
\hline Lama kerja & Jumlah & Rata-rata kapasitas \\
\hline$<15$ & 10 & $58.3 \mathrm{a}$ \\
$>15$ & 10 & $62.4 \mathrm{a}$ \\
\hline
\end{tabular}

Keterangan: Angka-angka yang diikuti huruf yang sama pada kolom yang sama menunjukkan nilai tidak berbeda nyata berdasarkan uji t-student dengan taraf $5 \%$.

\section{Tenaga Petik}

Jumlah tenaga kerja di Unit Perkebunan Rumpun Sari Kemuning Karanganyar tahun 2014 berjumlah 615 orang dengan luas areal 437.82 ha. Indeks Tenaga Kerja (ITK) yang dapat dicapai adalah 1.40 orang/ha, lebih rendah dibandingkan standar indeks tenaga kerja menurut Iskandar (1998) yaitu 1.50-2.00 orang/ha.

Tabel 10. Perbandingan jumlah pemetik di lapang dengan perhitungan tenaga petik

\begin{tabular}{lccc}
\hline \multirow{2}{*}{ Blok } & Luas areal (ha) & \multicolumn{2}{c}{ Jumlah tenaga petik (orang) } \\
\cline { 3 - 4 } & & Lapang & $\begin{array}{c}\text { Hasil } \\
\text { perhitungan }\end{array}$ \\
\hline OA 13 & 14.83 & 25 & 23 \\
OA 6 & 19.41 & 24 & 31 \\
OA 15 & 14.87 & 26 & 23 \\
OB 3 & 13.65 & 22 & 21 \\
OB 6 & 15.15 & 20 & 24 \\
OB 4 & 14.15 & 22 & 21 \\
\hline Jumlah & 92.06 & $139 \pm 2.22$ & $143 \pm 3.71$ \\
\hline
\end{tabular}

Tenaga kerja petik merupakan salah satu faktor terpenting bagi suatu perusahaan agribisnis dalam bidang perkebunan teh (Ongong dan Ochieng, 2013). Hasil penghitungan rasio tenaga petik tahun 2014 adalah $1.56 \mathrm{HK} \mathrm{ha}^{-1}$, sehingga untuk menyelesaikan sample areal produktif seluas 92.06 ha dengan target produksi basah sebesar $8580 \mathrm{~kg}$ dibutuhkan 143 tenaga petik per harinya sehingga dapat disimpulkan jumlah pemetik tiap hari masih kurang maksimal (Tabel 10).

\section{Sarana Panen dan Transportasi Pucuk}

Pucuk yang telah dipetik dari kebun harus segera ditransportasikan ke pabrik dalam keadaan yang segar sehingga kualitas pucuk tetap dalam kondisi optimal saat diolah. Sarana transportasi yang digunakan merupakan hal penting dalam menunjang kegiatan pemetikan. Penimbangan dan pengangkutan pucuk dari kebun dilaksanakan dua kali sehari yaitu pukul 09.30 WIB dan pukul 12.00 WIB. Kegiatan penimbangan dilakukan dua kali di kebun dan di pabrik kemudian diangkut menggukan truk dan mobil pickup.

Kapasitas angkut truk yang disewa oleh Unit Perkebunan Rumpun Sari Kemuning adalah $2578 \mathrm{~kg}$ tiap truk sedangkan kapasitas pickup 1549 kg. Unit Perkebunan Rumpun Sari Kemuning menyewa truk berjumlah 3 unit dan mobil pickup milik Unit Perkebunan Rumpun Sari Kemuning berjumlah 1 unit. Jumlah unit transportasi cukup untuk melakukan pengangkutan pucuk dari kebun ke pabrik meskipun kadang terdapat pucuk yang rusak karena adanya penjejalan waring pada saat pengangkutan pucuk teh.

\section{Produksi dan HOK berdasarkan Umur Pangkas}

Produksi perkebunan teh erat kaitannya dengan jumlah HOK pemetik tanaman teh. Hasil pengolahan data Produksi dan HOK pada Unit Perkebunan Rumpun Sari Kemuning dapat dilihat pada Tabel 11.

Produksi teh meningkat pada umur pangkas I dan II namun menurun pada umur pangkas III sedangkan pada umur pangkas IV produksi naik. Pada blok dengan umur pangkas I memiliki produksi $606742 \mathrm{~kg}$; pada umur pangkas II memiliki produksi 1032319 kg; pada umur pangkas III memiliki produksi 606 $742 \mathrm{~kg}$; serta umur pangkas IV memiliki produksi $856778 \mathrm{~kg}$. Pada produksi menunjukkan bahwa terjadi penurunan produksi teh berdasarkan umur pangkasnya. Produksi yang dihasilkan tidak stabil berdasarkan umur pangkasnya. Hal ini kurang sesuai dengan ketentuan produksi. Produksi mengalami penurunan seiring dengan bertambahnya umur tanaman teh. Hal ini juga yang menjadi ketentuan dalam kegiatan pemangkasan (Martini 2011).

Pada data HOK umur pangkas I terdapat jumlah HOK 18 976; umur pangkas II mengalami kenaikan hingga 31 402; umur pangkas III mengalami penurunan 17 126; dan umur pangkas IV meningkat sampai 26 498. Pada umur pangkas II jumlah HOK yang dibutuhkan 
mengalami kenaikan pada produksi pucuk teh mengalami kenaikan. Berdasarkan data produksi dan jumlah HOK di Unit Perkebunan Rumpun Sari Kemuning perbandingan prestasi dan HOK mengalami peningkatan sampai umur pangkas III kemudian menurun pada umur pangkas IV. Hal ini terjadi karena produksi pucuk teh akan mengalami penurunan seiring dengan bertambahnya umur pangkas walaupun terdapat luas areal yang lebih besar namun kualitas dan kuantitas teh menurun. Dalam manajemen pemanenannya masih perlu adanya perkembangan untuk memenuhi kebutuhan HOK yang disesuaikan dengan produksi yang dihasilkan guna meningkatkan efektivitas tenaga kerja pemetik di kebun.

Tabel 11. Produksi dan HOK Unit Perkebunan Rumpun Sari Kemuning tahun 2013

\begin{tabular}{ccccc}
\hline Umur pangkas & $\begin{array}{c}\text { Luas areal } \\
\text { produksi }\end{array}$ & $\begin{array}{c}\text { Produksi tahun } \\
(\mathrm{kg})\end{array}$ & HOK & $\begin{array}{c}\text { Produksi } \\
(\mathrm{kg} / \mathrm{HOK})\end{array}$ \\
\hline I & 69.55 & 581618 & 18976 & 31.19 \\
II & 86.53 & 1032319 & 31402 & 32.65 \\
III & 64.03 & 606742 & 17126 & 36.88 \\
IV & 93.03 & 856778 & 26498 & 32.80 \\
\hline Rata-rata & 78.30 & 769364.25 & 23500.5 & $33.38 \pm 2.44$ \\
\hline
\end{tabular}

Sumber : Laporan produksi tanaman Unit Perkebunan Rumpun Sari Kemuning 2013

\section{KESIMPULAN}

Pengelolaan pemetikan di Unit Perkebunan Rumpun Sari Kemuning sudah cukup baik apabila dilihat dari beberapa faktor seperti tinggi bidang petik, diameter bidang petik, tebal daun pemeliharaan, dan kapasitas pemetik. Tinggi bidang petik tanaman kurang dari $110 \mathrm{~cm}$. Diameter rata-rata bidang petik pada tanaman umur pangkas I-IV $104.4 \mathrm{~cm}$. Tebal daun pemeliharaan pada tanaman umur pangkas I-IV sudah efektif untuk memenuhi kebutuhan fotosintesis. Kapasitas petik sudah memenuhi ketentuan $60 \mathrm{~kg} /$ pemetik.

Hanca petik rata-rata Unit Perkebunan Rumpun Sari Kemuning adalah 2.093 ha/hari/mandor. Gilir petik yang diterapkan Unit Perkebunan Rumpun Sari Kemuning belum memenuhi standar yang telah ditetapkan yaitu 9-11 hari. Analisis petik sudah memenuhi ketentuan pabrik yaitu $>50 \%$ petikan medium.

Analisis pucuk lebih kecil dibandingkan dengan standar yaitu $40 \%$ pucuk memenuhi syarat (MS). Sarana transportasi pucuk di Unit Perkebunan Rumpun Sari Kemuning menggunakan truk yang disewa sudah mencukupi proses pengangkutan. Produksi dan HOK pada Unit Perkebunan Rumpun Sari Kemuning perlu adanya perkembangan pada kebutuhan tenaga petik teh yang mencakup HOK yang diperlukan.

\section{DAFTAR PUSTAKA}

Asrimelwati. 2008. Pengelolaan Pemangkasan Teh (Camellia sinensis (L.) O. Kuntze) di Kebun Tambak Sari PT Perkebunan Nusantara VIII Subang, Jawa Barat. S kripsi. Institut Pertanian Bogor, Bogor.
Dalimoenthe, S.L. 1999. Implikasi pemetikan secara mekanis terhadap produksi, mutu hasil olahan, dan kesehatan tanaman teh. Di dalam: Pusat Penelitian Teh dan Kina, editor. Prosiding Pertemuan Teknis Teh Nasional 1999; Bandung, Indonesia. Bogor (ID): PPTK. hlm $229-232$.

[Ditjenbun] Direktorat Jenderal Perkebunan. 2012. Statistik Perkebunan Indonesia 2011 - 2013 : Teh. Ditjenbun, Jakarta.

Fathan, J. 2013. Pengelolaan Pemetikan Tanaman Teh (Camellia sinensis (L) O. Kuntze) di Unit Perkebunan Bedakah PT Tambi Wonosobo, Jawa Tengah. S kripsi. Institut Pertanian Bogor, Bogor.

Johan, M.E. 2005. Pengaruh tinggi pangkasan dan tinggi jendangan terhadap pertumbuhan dan hasil pucuk basah pada tanaman teh asal biji. Bogor. J. Penelitian Teh dan Kina. 8(1-2) 43-48.

Johan, M.E., Dalimoenthe, S.L. 2009. Pemetikan pada Tanaman Teh. PPTK, Bandung. 24 hal.

Lelyana, Q. 2011. Studi pengelolaan pemetikan pucuk daun the (Camelia sinensis (L.) $O$. Kuntze) di unit perkebunan tanjungsari, PT Tambi, Wonosobo Jawa Tengah. Skripsi. Institut Pertanian Bogor, Bogor.

Martini, A. 2011. Pengelolaan Pemangkasan Tanaman Teh (Camellia sinensis (L.) O. Kuntze) di Unit Perkebunan Rumpun Sari Kemuning, Karanganyar, Jawa Barat. Skripsi. Institut Pertanian Bogor, Bogor. 
Ongong, J.O., Ochieng, A. 2013. Innovation in the tea industry: the case of kericho tea, Kenya. Global Journal of Management and Business Research. 13(1):11-12.

[PPTK Gambung] Pusat Penelitian Teh dan Kina Gambung. 2006. Implementasi teknologi untuk mencapai industri teh berkelanjutan. Di dalam: Pusat Penelitian Teh dan Kina Gambung, editor. Prosiding Pertemuan Teknis Industri Teh Berkelanjutan; 12-13 September 2006; Agro Gunung Mas PTPN VIII Bogor, Indonesia. PPTK Gambung, Bogor. hlm 57 - 67.
[PPTK Gambung] Pusat Penelitian Teh dan Kina Gambung. 2010. Standar Operasi Prosedur Pemetikan. Pusat Penelitian Teh dan Kina Gambung, Bogor.

Rahmadona, L. 2012. Pengelolaan pemetikan teh (Camellia sinensis (L.) O. Kuntze) di Unit Perkebunan Tambi, PT Tambi, Wonosobo, Jawa Tengah. Skripsi. Institut Pertanian Bogor, Bogor.

Setyamidjaja, D. 2000. Budidaya dan Pengolahan Pasca Panen Tanaman Teh. Yogyakarta (ID): Kanisius. Walpole RE. 1992. Pengantar Statistika Ed ke-3. Sumantri $\mathrm{B}$, penerjemah. Jakarta (ID): PT Gramedia Pustaka Utama. Terjemahan dari: Introduction to Statistics 3rd edition. 515 halaman. 